American Journal of Pharmaceutical Education 2016; 80 (6) Article 101.

\title{
RESEARCH
}

\section{A Retrospective Study on Students' and Teachers' Perceptions of the Reflective Ability Clinical Assessment}

\author{
Cherie Tsingos-Lucas, MPS, BPharm, ${ }^{a}$ Sinthia Bosnic-Anticevich, PhD, BPharm(Hons), ${ }^{b}$ \\ Lorraine Smith, $\mathrm{PhD}, \mathrm{BA}(\mathrm{Hons})^{\mathrm{a}}$ \\ ${ }^{a}$ The University of Sydney, Sydney, New South Wales, Australia \\ ${ }^{\mathrm{b}}$ The Sydney Medical School, University of Sydney, New South Wales, Australia \\ Submitted June 8, 2015; accepted August 27, 2015; published August 25, 2016.
}

Objective. To evaluate student and teacher perceptions of the utility of the Reflective Ability Clinical Assessment (RACA) in an undergraduate pharmacy curriculum at an Australian university.

Methods. A mixed-method study comprising the administration of a 7-item student survey on a 6-point Likert-type scale and a 45-minute focus group/phone interview with teachers.

Results. Student $(n=199)$ and teaching staff respondents $(n=3)$ provided their perceptions of the implementation of the new educational tool. Student responses showed significant positive correlations between self-directed learning, counseling skills, relevance to future practice, and performance in an oral examination. Seven key themes emerged from the teacher interviews.

Conclusion. The study revealed both students and teachers perceive the RACA as an effective educational tool that may enhance skill development for future clinical practice.

Keywords: Reflective Ability Clinical Assessment (RACA), reflection, pharmacy education, student/teacher perceptions

\section{INTRODUCTION}

Reflection is a metacognitive strategy for the development of clinical reasoning expertise. ${ }^{1}$ Research posits that developing good reflective thinking skills can enhance students' ability to make better decisions, thus, improving their clinical decision making skills for future clinical outcomes. ${ }^{1-3}$ These skills are important attributes for future pharmacists. ${ }^{4,5}$ If attributes such as reflective thinking skills enhance decision-making capabilities, then poor reflective thinking skills may hinder clinical decision-making ability. To improve reflective ability of a cohort of second-year undergraduate pharmacy students, an educational intervention that included the Reflective Ability Clinical Assessment (RACA) was integrated into a pharmacy curriculum. ${ }^{6}$

The RACA involves three key elements: a clinical scenario, a video podcast, and a reflective statement. The details of the RACA were described in a previous paper. ${ }^{6}$ The aims of introducing the RACA process into curricula was to enhance the reflective-thinking process, engage the student learning process, and facilitate skill development such as counseling and self and peer reflection to improve

Corresponding Author: Cherie Tsingos-Lucas, Pharmacy Bank Building A15, Room N372, The University of Sydney, Sydney NSW 2006, Australia. Tel: +61-2-9036-5437. Fax: +61-2-9036-5063. E-mail: cherie.tsingos@sydney.edu.au future practice. The RACA requires students to reflect on the whole task (ie, the three elements) and write reflectively on how they can overcome challenges, how their previously held beliefs, attitudes, and assumptions may have changed, how their strengths and skills may have developed, and how they could improve future practice. A student's approach to learning through reflection may play a part in developing a deeper way of thinking. ${ }^{7}$ Also, the implementation of reflective activities into an undergraduate pharmacy curriculum can enhance the reflective ability of students. ${ }^{6}$ Moreover, reflective processes implemented in health education settings can enhance decisionmaking skills, which may be useful for future clinical practice. ${ }^{2,8,9}$ Furthermore, a Belgian study involving midwifery students $(n=142)$ investigated student perceptions of the implementation of reflective-writing activities at different stages of their clinical training and reported value in such exercises. ${ }^{10}$

Despite a plethora of published literature on the development and use of reflective activities, strategies, tools, and guides in professional health education, ${ }^{2,4,5,8,11-51}$ few studies investigate the views from experienced health professionals. ${ }^{52-54}$ Additionally, limited studies investigate students' views ${ }^{10,55-57}$ or teachers' views $^{58}$ on the implementation of reflective learning activities in health education. Only one study addressed perceptions of students and teachers on the impact of 


\section{American Journal of Pharmaceutical Education 2016; 80 (6) Article 101.}

reflective-learning activities in a health professional education program. ${ }^{59}$ However, that study was conducted on postregistration (ie, licensed) nurses and not on undergraduate and/or pharmacy students. There is a gap in the published literature regarding perceptions of pharmacy students and pharmacy educators on the implementation of reflective activities into a pharmacy curriculum. Bridging this gap may provide greater insights and understandings into the integration of reflective learning activities and tools (such as the RACA) in an undergraduate pharmacy curriculum. Insights from such inquiries may help develop and sustain novel educational tools and benefit future pharmacy cohorts.

This is the first study in pharmacy education that investigates perceptions of pharmacy students and teachers on implementation of reflective activities. Building on previous studies, this study explores the relationship of these groups' perceptions of the RACA and its perceived potential value as a learning tool to improve the reflective ability and counseling skills for future clinical practice.

\section{METHODS}

This research project was a retrospective study and an extension to a previous study that involved a quasiexperimental cross-over design. The previous study involved an intervention-control group design with repeated measures, which showed that pharmacy students' reflective thinking ability changed when reflective educational activities were integrated into a curriculum $(p=0.01){ }^{6}$

Before commencing this study, approval was sought and granted from the University of Sydney Human Research Ethics Committee. Participants (students and teaching staff) were voluntarily recruited for the study. The current study invited students (18 years and older, $\mathrm{N}=264$ : males $\mathrm{n}=92$; females $\mathrm{n}=172$ ) who were enrolled in the course in the previous semester (2014) when the RACA was implemented. Students were asked to rate the impact and effectiveness of the RACA on their learning. Students were recruited for the study via a notice on the Blackboard Learning Management System (LMS). Using a mixed-method approach, a 7-item survey on a 6-point Likert-type scale (Appendix 1) was administered to students who participated in the study $(\mathrm{n}=199)$, and a focus group or interview session was conducted with teaching staff participants $(n=3)$.

The student survey was a structured 7-item questionnaire related to student perceptions of the utility of the RACA for pharmacy education. Questions were derived from the educational underpinnings of reflective learning outcomes. ${ }^{50,51,60-62}$ For example, question 1 was derived from evidence that reports the reflection process is a challenging exercise. ${ }^{14,15,63}$ Question 2 indicated that reflective activities can assist self and peer reflection and help engage student learning. ${ }^{30,33}$ Question 3 was based on previous literature that stated enhanced reflective ability can improve self-directed learning skills. ${ }^{4,64}$ Question 4 was derived from evidence engaging in reflective activities can improve future practice. ${ }^{2,5}$ Questions 5 and 6 were drawn from literature that indicated the reflective process is an important attribute for health professions as it may enhance other skills, such as communication or counseling. ${ }^{33,65}$ Finally, question 7 related a key element to effective reflection: the ability to view situations from different perspectives. ${ }^{4,51,62,66}$ Thus, questions on the survey were intended to assess the impact of the RACA on student learning (self-directed and reflective learning skills), counseling skills, and relevance for future practice (Appendix 1). Teaching staff not involved with the implementation of the RACA in the previous year distributed the survey. Survey administration was conducted during allocated tutorial/laboratory sessions. A drop off box for completed questionnaires was organized for collection. Data analyses of the students' perceptions were conducted using SPSS, v20 (SPSS, Armonk, NY) ${ }^{67}$ Descriptive statistics were conducted and analyzed. As the student survey involved seven items on a 6-point Likert-type scale, each point was allocated a score between 1 (strongly disagree) to 6 (strongly agree) (Appendix 1).

Quantitative measures included descriptive analyses and correlation statistical procedures. Descriptive analyses were conducted to identify the extent of a student's agreement to each survey question. Correlations were conducted to explore the extent to which students perceived the RACA to be of value to their learning, counseling, and skill development. Statistical significance was set at $p<0.05$.

Four teaching staff were involved with implementing the RACA in the curriculum. Of the four teaching participants, three were voluntarily recruited for the project via e-mail. Two had clinical experience, ranging from five years to 15 years. The third had extensive pharmacy research experience. All teacher participants held clinical educator positions in the Faculty of Pharmacy and had taught across the bachelors of pharmacy (BPharm) curriculum at various year levels from between one to 12 years.

The integration of the RACA occurred during the final semester in 2014. However, the project investigating student and teacher perceptions was conducted the following semester in 2015. For this reason, one teaching participant was unable to be involved with the focus group because of work commitments and distance from the 


\section{American Journal of Pharmaceutical Education 2016; 80 (6) Article 101.}

university campus. However, this teacher participant (teacher participant 3) opted for a phone interview immediately following the completed focus group session with teacher participants 1 and 2. The focus group session ran for approximately 45 minutes and was conducted by an experienced researcher and teacher not directly involved with the implementation of the RACA. Interviews were transcribed, and content analysis identified several key themes regarding their overall perception of the utility of the RACA. In the reported findings, teachers are identified as teacher participants 1,2 , and 3 . The interview schedule included semi-structured questions to explore the main issues and concepts surrounding the implementation of the RACA (Appendix 2, Table 1).

\section{RESULTS}

From a cohort of 264 students, 199 surveys (75\% response rate) were completed voluntarily. Descriptive statistics were conducted (Appendix 2, Table 2) and reported student responses to each question (measure) on the survey. Descriptive statistics indicated that the highest means were allocated to question 4 [mean $=4.6$ $(\mathrm{sd}=1.16)]$ and question 5 [4.5 (1.07)], indicating students either mildly agreed, agreed, or strongly agreed $(89 \%)$ that the RACA was relevant to future clinical practice, and $86 \%$ of students mildly agreed, agreed, or strongly agreed that it was a valuable resource that helped them improve their counseling skills. In contrast, question 2 had the lowest mean value [4.0, (1.14)] compared to the other measures, indicating that the RACA had less impact on students' interest in pharmacy learning. While this question had the lowest mean value, $73 \%$ mildly agreed, agreed, or strongly agreed that the RACA helped them become more interested in learning. Furthermore, $75 \%$ perceived that the introduction of the reflective learning activities into their classroom environment helped them see things from different perspectives (question 7, Table 2).

Correlation statistical procedures were undertaken to investigate the relationship of different aspects of the RACA with perceived value for future clinical practice. Correlations of the measures were conducted (Appendix 2, Table 3). All correlations except one were significant $(p<0.01)$. The strongest positive linear correlations occurred between question 2 (The RACA helped me become more interested in my learning in pharmacy) and question 3 (The RACA helped me become a more selfdirected learner $),(\mathrm{r}(196)=0.7, p<0.01)$. Similarly, a moderate positive linear correlation was evident with question 5 (The RACA helped me improve my counseling skills) and question 4 (I could see the relevance of the RACA to future clinical practice in pharmacy),
( $\mathrm{r}(196)=0.61, p<0.01)$ and question 5 (The RACA helped me improve my counseling skills) and question 6 (The RACA provided me with the skills to perform to the best of my ability in the final oral examination), $(\mathrm{r}(195)=0.6, p<0.01)$. There was no correlation between question 1 (The RACA was challenging) and question 6 (The RACA provided me with the skills to perform to the best of my ability in the 2014 oral examination).

Teaching staff provided valuable insights regarding the implementation of the RACA. The transcribed focus group and interview sessions identified seven key themes: (1) the usefulness of the implementation of the RACA into curriculum; (2) value for future tasks and clinical practice; (3) student experience; (4) student engagement in their learning; (5) challenges; (6) suggestions for its sustainability for future cohorts; and (7) suggestions for improvement.

Teacher perceptions of the RACA's usefulness were similar. The implementation of this novel learning and teaching tool was perceived by teacher participants to be a highly useful educational model. All teacher participants agreed that the reflective activities were a useful educational tool to help students start developing their clinical application process. Example comments included: "I think reflection in general is very good in clinical practice...that clinical application of reflection became useful" (teacher participant 1); "It also helped the students identify weaknesses and strengths... what you are missing, what can you do better. . .so I think in that sense it was a great concept" (teacher participant 2);

Teacher participants reported that introducing real hospital and community cases allowed students to be self-directed with their learning. Perhaps an explanation for this relates to students really thinking about a critical incident or event in terms of someone's biases, beliefs and assumptions, as originally described by Dewey (1933). ${ }^{60}$ Furthermore, teacher participants reported that use of video podcasts to enhance student counseling skills allowed for formative self and peer reflection and feedback, which gave them an opportunity to become better prepared for the final assessment tasks. One teacher participant reported that the RACA was a useful tool that gave students the opportunity to improve their academic performance in the final oral examination: "See(ing) themselves and then reflect(ing) on themselves...probably prepared them better for their final exams" (teacher participant 3).

Teacher participants perceived the RACA to be a valuable learning strategy because of its potential to assist clinical decision-making skills. One of the key elements derived from this theme indicated that teacher participants would like the continuation and 


\section{American Journal of Pharmaceutical Education 2016; 80 (6) Article 101.}

formalization of this learning and teaching strategy throughout the BPharm curricula. From teacher participant 1: "I would go out and say well I'd love to see it mandatory, I'd like to see it replacing a lot of the counseling in fourth year, in particular because. . .students can give you a very nice written piece of clinical advice but put them in a reflective scenario, put them in a counseling session face to face with someone, you see a completely different side to that written performance. . .it would be good to see that continuation carry through into third and fourth year (building on) what clinical decisions(they would) make differently."

The general consensus regarding the student experience of the implementation of the RACA was that initially students were anxious and apprehensive as they indicated they were not sure of the purpose and process, given it was a new strategy. Teacher participant 2 acknowledges that some students found this novel learning strategy challenging: “. . . they struggled with it because I don't think they had done anything like this before." Results from the student survey reported that $76 \%$ of students mildly agreed, agreed, or strongly agreed that the RACA was a challenging exercise (Appendix 2, Table 2). Perhaps this reflected some of the apprehension among students.

However, despite this the students did not perceive this as a negative experience, according to teacher participant 1; "there was no strong dislike ...most ended up enjoying the role plays in class and then the role play they had to do in the videotape."

All teacher participants felt that the implementation of reflective modules into curriculum enhanced student engagement in their learning tasks. Teacher participants reported the method of teaching clinical modules with reflective-thinking processes provided a platform for students to ask more engaging questions and to encourage deeper thinking. "Students quite liked the cases and the way ... little by little was revealed...was quite engaging and sparked interesting discussions....the reflective thinking module helped the students think more about experiences and learning from mistakes...it's different to how they're used to learning as well and I think that's definitely a good thing to have as it mixes it up a little bit" (teacher participant 3).

Teacher participant 3 also perceived that the reflective-learning modules allowed students to think about their decisions based on different perspectives. For example, the clinical cases had a number of issues to address and, by revealing one part of the case at a time, students were encouraged to think about the next step to take and the reasons why they made that decision. In terms of the video podcasts and the reflective statements, which were both self-directed learning activities, students were encouraged to stop, think, and reflect on their counseling and clinical decisions as well as their peers. "This strategy was thought provoking. . . learning about cold and flu gets them thinking, just because it's a runny nose, it could be a million other things you know and that sort of makes them want to question more" (teacher participant 2).

Furthermore, teacher participants reported that the introduction of reflective activities involving real cases stimulated student learning: "I really think they like to see real cases because at least I think it gets them excited about their idea of what they will be doing and seeing in a clinical role." (teacher participant 3 ).

In terms of teacher participants' perceived challenges of implementing this strategy in future curriculum, challenges included the amount of time needed to download each video podcast and to grade video podcasts and reflective statements. Time spent downloading each video podcast from Blackboard depended largely on the size of the file. Although all videos were no longer than five minutes, some file sizes varied considerably.

All teacher participants agreed that the new learning and teaching module would be integral for student learning. However, this would only be possible if the strategy could be sustainable. For this to occur, processes need to be established. "I think it's a really good idea to have students doing this kind of thing so I hope it's something that is maintained and I hope that there are resources available to do so because I think it's different to how they're used to learning as well and I think that it is definitely a good thing to have that" (teacher participant 3 ). Some of the key issues to its sustainability were time allocation in the curriculum, additional staff training sessions, and enough funding to support grading components of the RACA.

Finally, teacher participants proffered a variety of views regarding what improvements could be made in the implementation of the RACA into curriculum. These included asking students to produce a reflective speech rather than a written reflective statement, and providing students with examples, thus using the "modeling" strategy.

\section{DISCUSSION}

This is the first published study in pharmacy education context that explores both student and teacher perceptions of the utility of a novel reflective learning tool. This exploratory study (with predominantly female participants and indicative of the male/female student ratio in all pharmacy schools in Australia) highlighted key findings that support implementation of the RACA into pharmacy curricula. Both student surveys and teacher participant focus group/interview sessions demonstrated 


\section{American Journal of Pharmaceutical Education 2016; 80 (6) Article 101.}

the value of continuous use of the RACA in future pharmacy cohorts, with teacher participants indicating support for the formalization of this educational tool. Enhanced reflective ability can assist with the development of skills essential for future clinical practice. ${ }^{2,4,5,30,68-70}$ The initial aim for the implementation of the RACA was to enhance reflective ability, selfdirected learning capacity, counseling skills, and interest in pharmacy learning.

Beyond these aims, it was implemented as an opportunity for students to enhance these skills prior to their end-of-year oral examination. Descriptive statistics reported overall agreement by the majority of students that the RACA helped enhance their skill development for reflective ability, self-directed learning capacity, and counseling skills. The majority of students further viewed the RACA as a tool that provided them with the skills to perform in the end-of-year oral examination and agreed that this learning tool helped them become more interested in their learning. A reason for this increased interest in pharmacy learning may relate to the introduction of a variety of teaching and learning strategies involved with the implementation of the RACA, such as the use of video podcasts, real hospital case discussions, and reflective writing. A key element to effective reflective learning is the skill to view situations from different perspectives, thus allowing for better informed decisions. ${ }^{4}$ This study reported a majority of students perceived the introduction of reflective learning activities into curriculum helped them see things from different perspectives.

Correlations were conducted to explore the extent to which students perceived the RACA to be of value to their learning and skill development. Interestingly, the student survey data showed the strongest positive linear relationships between interest in learning and motivation for selfdirected learning, between counseling skill development and its perceived positive impact on their final oral examination, and between counseling skill development and its perception as a relevant skill for future practice. This study also suggests that enhanced interest in learning may be associated with developing skills for future practice. Providing students with the tools for self-directed learning positively relates to their interest in the learning task. Furthermore, once students see the relevance of a learning task or learning tool to their future tasks or practice, student engagement in that task may lead to better skill development.

The only nonsignificant correlation related to question 1 (the RACA was challenging) and question 6 (it provided me with the skills to perform better in the end of year oral examination), indicated that, with this dataset, there was no relationship between the degree of challenges of the RACA exercise and performance in the end-of-year oral examination. This result suggests that other aspects of the oral examination require further consideration. For example, the examination is the first oral assessment the students experience in the course. Secondly, the reflective-thinking process may have not been a consideration for this high-stakes, 5-minute examination as there was little time to stop and reflect. Thirdly, the dataset comprised of second-year students, who had a smaller bank of clinical experiences to draw on compared to students in third and fourth years.

Research using reflective models and reflective assessment tasks to enhance student learning reported that students found these tasks challenging. ${ }^{57}$ Quantitative measures revealed that students thought the RACA was challenging. This finding may be a result of it being a new strategy and not being taught or facilitated in previous pharmacy cohorts. Our qualitative data reported by teacher participants showed that students were apprehensive about the implementation of a new way of learning through reflective activities. In particular, they reported that some students were anxious, confused, and unsure of how the RACA related to their learning, their assessment grades, and future clinical practice. This "tension" was also evident in a previous studies. ${ }^{10,55,57}$ The first study conducted on midwifery students involved two reflective writing components that were summatively assessed and were perceived by some students as "challenging" compared to previous exercises. Some students from this previous study reported that they felt a need to write something down as a positive reflection, rather than a negative reflection for "fear" of how this exercise would be assessed. $^{10}$

The second study involved medical students who were concerned about the transparency of assessing reflective writing and expressed "tension" with writing reflections that may be for the "public" view. ${ }^{55}$ The third study conducted on undergraduate nursing students revealed that students found the tasks "confusing and frustrating," as it was challenging to choose and use a model of reflection and write a 3000-word reflective essay on caring for a patient with chronic disease when they had little or no clinical experience. ${ }^{57}$ Despite these misgivings, students from these studies acknowledged that the reflective exercises were valuable and placed importance on reflecting on learning experiences, ${ }^{10,55}$ and students valued the independence and self-directed learning that stemmed from these activities. ${ }^{57}$ Furthermore, previous research into student perceptions of reflective learning in health education showed that they at least gained insights and new understandings about their strengths and weaknesses as future health professionals. ${ }^{56}$ 


\section{American Journal of Pharmaceutical Education 2016; 80 (6) Article 101.}

The results of the current study support these findings as teacher participants also reported that students felt anxious about the new strategy and assessment tasks because they had not previously experienced learning with this approach. However, teachers felt that students started to grasp the concept and its importance over time, and this led to more in-depth tutorial/laboratory discussions about students' strengths, weaknesses, challenges, and assumptions. Furthermore, teacher participants perceived that disclosing case information gradually to students as the role plays unfolded allowed them to think and reflect on the different perspectives and the type of informed decisions that needed to be made. Other reflective activities, such as the video podcasts and reflective writing components, allowed for enhanced self and peer reflection on the tasks. These skills were perceived by teachers to be essential in developing future reflective pharmacy practitioners.

Despite teacher participants receiving some training related to implementing the RACA in curriculum, they reported the need to expand on staff training prior to its implementation. This was perceived to be necessary for its sustainability for future cohorts.

Teacher participants also reported challenges to the process. Initially, teachers were concerned with the technological challenges of the exercises. However, once the research project was near completion, other perceived challenges emerged. These included time allocation for staff training to ensure effective facilitation of the modules into the curriculum timetable, concerns about enough funding resources to support grading, and downloading the video podcasts from Blackboard in a more timely and efficient manner. Teacher participants recommended improvements in the implementation of the RACA including providing students with external devices (for example flash drives) to be submitted rather than uploading and downloading the reflective statement, scenario, and video podcasts to Blackboard. This will assist with time and efficiency of grading and would also allow students to swap their external devices and learn from each other in a laboratory/tutorial setting. This process could further enhance peer reflection.

Reflective practice activities in the form of reflective writing tasks are of considerable value in health professions education as an effective learning tool. ${ }^{10}$ Although there were some perceived limitations by students and teacher participants regarding the implementation of the RACA, it was considered a valuable, useful, and productive educational tool, which could potentially help students with clinical practice. One explanation for this may be that the RACA allowed a forum for students to question themselves and their assumptions introspectively and encouraged them to think beyond the clinical cases by thinking from different perspectives.

Teacher participants also reported that the RACA was effective in enhancing student engagement in the task. Positive responses by teacher participants revealed that the RACA implementation "sparked interesting and thought provoking" class discussions as it required the students to think about reflecting on a task. All teacher participants reported their support for the continuous development and refinement of the RACA for ongoing use in future pharmacy cohorts.

A limitation of this study was that it involved only one pharmacy school. Our study suggests that with the proper resources, time allocated in curriculum for teaching staff training of reflective practices, and student feedback on reflective practice activities may allow for continuation of this educational tool, thereby, providing a springboard to enhance student reflective capacity. The outcomes of this study support our previous work which involved testing the effects of implementation of the RACA in a quasi-experimental cross-over interventioncontrol study with repeated measures. ${ }^{6}$ This previous study showed that integrating reflective activities into a curriculum was associated with an increase in reflective and critical reflective thinking ability of a cohort of students.

As reflective ability has the potential to assist students to make better informed clinical decisions prior to and during counseling and enhance self-directed and lifelong learning, implementation of activities that support this skill development should be given consideration when developing and designing the curriculum. The results of the current study will inform future interventions and improvements for implementation of the RACA into pharmacy curricula and allow for better sustainability of this valuable educational tool. Data is currently being analyzed and the relationship between the RACA process and students' academic performance outcomes will form the basis of a future publication.

\section{CONCLUSION}

Developing reflective-learning activities and novel strategies such as the RACA for integration into curriculum involves careful considerations. The perceptions from students and staff are important to consider so that reflective-thinking activities are fine-tuned and scaffold across curricula to benefit future cohorts. This study provides insights into the effects, value, and usefulness of a new educational tool. Most students, despite initial apprehensive thoughts, ultimately felt the RACA was a useful and valuable component of the curriculum, with the majority reporting its greatest value to assisting them with 


\section{American Journal of Pharmaceutical Education 2016; 80 (6) Article 101.}

counseling skills. Furthermore, the majority of students indicated support for its relevance to enhance their skills for future clinical practice. All teacher participants believed this educational tool, with improvements, could be an essential component of the curricula.

\section{ACKNOWLEDGMENTS}

The authors would like to acknowledge and thank the three teacher participants for their participation in a focus group or interview session and the students from the Faculty of Pharmacy who volunteered for this study. The authors extend their thanks to the educators who offered to distribute surveys to students.

\section{REFERENCES}

1. Cutrer WB, Sullivan WM, Fleming AE. Educational strategies for improving clinical reasoning. Curr Probl Pediatr Adolesc Health Care. 2013;43:248-257.

2. Mamede S, Schmidt HG, Penaforte JC. Effects of reflective practice on the accuracy of medical diagnoses. Med Educ. 2008;42(5):468-475.

3. Ajjawi R, Loftus S, Schmidt H, Mamede S. Clinical reasoning: the nuts and bolts of clinical education. In Delany $\mathrm{C}$ and Molloy C (eds): Clinical education in The Health Professions. Chatswood, NSW: Elsevier; 2009.

4. Tsingos C, Bosnic-Anticevich S, Smith L. Reflective practice and its implications for pharmacy education. Am J Pharm Educ. 2014;78 (1):Article 18.

5. Tsingos C. Reflective practice: learning from experience. J Pharm Pract Res. 2013;43(3):249-250.

6. Tsingos-Lucas C, Bosnic-Anticevich S, Schneider C, Smith L. The effect of reflective activities on reflective thinking ability in an undergraduate pharmacy curriculum. Am J Pharm Educ. 2016; 80(4). Article 65.Am J Pharm Educ. 2015.

7. Tsingos C, Bosnic-Anticevich S, Smith L. Learning styles and approaches: Can reflective strategies encourage deep learning? Curr Pharm Teach Learn. 2015;7(4):492-504.

8. Wetmore AO, Boyd LD, Bowen DM, Pattillo RE. Reflective blogs in clinical education to promote critical thinking in dental hygiene students. J Dent Educ. 2010;74(12):1337-1350.

9. Croke E. The use of structured reflective journal questions to promote fundamental development of clinical decision-making abilities of the first semester nursing student. Contemp Nurse. 2004; 17(1-2):125-136.

10. Embo MP, Driessen E, Valcke M, Van Der Vleuten CP. Scaffolding reflective learning in clinical practice: a comparison of two types of reflective activities. Med Teach. 2014;36(7):602-607.

11. Asselin ME. Using reflection strategies to link course knowledge to clinical practice: the RN-to-BSN student experience. J Nurs Educ. 2011;50(3):125-133.

12. Aronson L, Niehaus B, Hill-Sakurai L, Lai C, O’Sullivan PS. A comparison of two methods of teaching reflective ability in Year 3 medical students. Med Educ. 2012;46(8):807-814.

13. Aronson L, Niehaus B, Lindow J, Robertson PA, O'Sullivan PS. Development and pilot testing of a reflective learning guide for medical education. Med Teach. 2011;33(10):e515-e521.

14. Boud D, Walker D. Promoting reflection in professional courses: the challenge of context. Stud High Educ. 1998;23(2):191-206.
15. Butani L, Blankenburg R, Long M. Stimulating reflective practice among your learners. Pediatrics. 2013;131(2):204-206. 16. Bernard AW, Gorgas D, Greenberger S, Jacques A, Khandelwal $\mathrm{S}$. The use of reflection in emergency medicine education. Acad Emerg Med. 2012;19(8):978-982.

17. Budzinski JW, Farrell B, Pluye P, et al. An online knowledge resource and questionnaires as a continuing pharmacy education tool to document reflective learning. Am J Pharm Educ. 2012;76(5): Article 82.

18. Briceland LL, Hamilton RA. Electronic reflective student portfolios to demonstrate achievement of ability-based outcomes during advanced pharmacy practice experiences. Am J Pharm Educ. 2010;74(5):Article 79.

19. Boenink AD, Oderwald AK, De Jonge P, Van Tilburg W, Smal JA. Assessing student reflection in medical practice. The development of an observer-rated instrument: reliability, validity and initial experiences. Med Educ. 2004;38(4):368-377.

20. Chirema KD. The use of reflective journals in the promotion of reflection and learning in post-registration nursing students. Nurse Educ Today. 2007;27(3):192-202.

21. Constantinou M, Kuys SS. Physiotherapy students find guided journals useful to develop reflective thinking and practice during their first clinical placement: a qualitative study. Physiotherapy. 2013;99 (1):49-55.

22. Carr S, Carmody D. Experiential learning in women's health: medical student reflections. Med Educ. 2006;40(8):468-774.

23. Duke S, Appleton J. The use of reflection in a palliative care programme: a quantitative study of the development of reflective skills over an academic year. J Adv Nurs. 2000;32(6):1557-1568. 24. Droege M. The role of reflective practice in pharmacy. Educ Health. 2003;16(1):68-74.

25. Fischer MA, Haley HL, Saarinen CL, Chretien KC. Comparison of blogged and written reflections in two medicine clerkships. Med Educ. 2011;45(2):166-175.

26. Forrest JL. Treatment plan for integrating evidence-based decision making into dental education. J Evid Base Dent Pract. 2006;6(1):72-78.

27. Fryer-Edwards K, Arnold RM, Baile W, Tulsky JA, Petracca F, Back A. Reflective teaching practices: an approach to teaching communication skills in a small-group setting. Acad Med. 2006;81 (7):638-644.

28. Greaves JD, Gupta SK. Portfolios can assist reflective practice and guide learning. Curr Anaesth Crit Care. 2003;14(4):173-177. 29. Gavaza P, Smith B, Adkins D. Effect of an introductory pharmacy practice experience geriatric rotation on pharmacy students' learning outcomes: a qualitative study. Consult Pharm. 2012;27(12):849-856.

30. Hanya M, Yonei H, Kurono S, Kamei H. Development of reflective thinking in pharmacy students to improve their communication with patients through a process of role-playing, video reviews, and transcript creation. Curr Pharm Teach Learn. 2014;6 (1):122-129.

31. Horton-Deutsch S, McNelis AM, Day PO. Developing a reflection-centered curriculum for graduate psychiatric nursing education. Arch Psychiatr Nurs. 2012;26(5):341-349.

32. Hanson K, Alexander S. The influence of technology on reflective learning in dental hygiene education. J Dent Educ. 2010;74 (6):644-653.

33. Hill K, Hamilton J. Using videoed simulated clinical interaction to promote communication skills and reflective practice for overseasborn medical students. Commun Med. 2013;10(1):1-11. 


\section{American Journal of Pharmaceutical Education 2016; 80 (6) Article 101.}

34. Kitchen M. Junior doctors' guide to portfolio learning and building. Clin Teach. 2012;9(5):308-311.

35. Kostrzewski AJ, Dhillon S, Goodsman D, Taylor KMG. The impact of portfolios on health professionals' practice: a literature review. Int $J$ Pharm Pract. 2008;16(6):339-345.

36. Koole S, Dornan T, Aper L, et al. Using video-cases to assess student reflection: development and validation of an instrument. $B M C$ Med Educ. 2012;12(22):1-8.

37. Kember D. Determining the level of reflective thinking from students' written journals using a coding scheme based on the work of Mezirow. Int J Lifelong Educ. 1999;18(1):18-30.

38. Lachman $\mathrm{N}$, Pawlina $\mathrm{W}$. Integrating professionalism in early medical education: the theory and application of reflective practice in the anatomy curriculum. Clin Anat. 2006;19(5):456-460.

39. Lonie JM. Learning through self-reflection: understanding communication barriers faced by a cross-cultural cohort of pharmacy students. Curr Pharm Teach Learn. 2010;2(1):12-19.

40. McKenna V, Connolly C, Hodgins M. Usefulness of a competencybased reflective portfolio for student learning on a masters health promotion programme. Health Educ J. 2011;70(2):170-175.

41. Markey L, Farvis R. Reflective Practice in an acute setting. Nurs Times. 2014;110(24):16-18.

42. Johns C. Guided reflection. Reflective Practice in Nursing. Oxford: Blackwell Scientific; 1994.

43. Moon J. Reflective Journals: A handbook for Reflective Practice and Professional Development. 2nd ed. London: Routledge Falmer; 2006.

44. Plaza CM, Draugalis JR, Slack MK, Skrepnek GH, Sauer KA.

Use of reflective portfolios in health sciences education. Am J Pharm Educ. 2007;71(2):Article 34.

45. Richardson G, Maltby H. Reflection-on-practice: enhancing student learning. J Adv Nurs. 1995;22(2):235-242.

46. Sandars J. The use of reflection in medical education: AMEE Guide No. 44. Med Teach. 2009;31(8):685-695.

47. Saltman DC, Tavabie A, Kidd MR. The use of reflective and reasoned portfolios by doctors. J Eval Clin Pract. 2012;18(1):182-185. 48. Tate S. Educating for reflective practice. J Atern Complement Med. 2003;9(5):773-777.

49. Wald HS, Reis SP. Beyond the margins: reflective writing and development of reflective capacity in medical education. J Gen Intern Med. 2010;25(7):746-749.

50. Schön DA. Educating the Reflective Practitioner. San Francisco, CA; Jossey-Bass; 1987.

51. Schön DA. The Reflective Practitioner: How Professionals Think In Action. Gower House, England: Ashgate Publishing Ltd; 1995.

52. Asselin ME, Fain JA. Effect of reflective practice education on self-reflection, insight, and reflective thinking among experienced nurses: a pilot study. J Nurses Prof Dev. 2013;29(3):111-119. 53. Asselin ME, Schwartz-Barcott D, Osterman PA. Exploring reflection as a process embedded in experienced nurses' practice: a qualitative study. J Adv Nurs. 2013;69(4):905-914.
54. Black PE, Plowright D. Exploring pharmacists' views about the contribution that reflective learning can make to the development of professional practice. Int J Pharm Pract. 2007;15(2):149-155. 55. Vivekananda-Schmidt P, Marshall M, Stark P, Mckendree J, Sandars J, Smithson S. Lessons from medical students' perceptions of learning reflective skills: a multi-institutional study. Med Teach. 2011;33(10):846-850.

56. Tsang AK, Walsh LJ. Oral health students' perceptions of clinical reflective learning - relevance to their development as evolving professionals. Eur J Dent Educ. 2010;14(2):99-105. 57. Turner DS, Beddoes L. Using reflective models to enhance learning: experiences of staff and students. Nurs Educ Pract. 2007;7 (3):135-140

58. Driessen EW, Van Tartwijk J, Overeem K, Vermunt JD, Van Der Vleuten CPM. Conditions for successful reflective use of portfolios in undergraduate medical education. Med Educ. 2005;39 (12):1230-1235.

59. Bulman C, Lathlean J, Gobbi M. The concept of reflection in nursing: Qualitative findings on student and teacher perspectives. Nurse Educ Today. 2012;32(5):e8-e13.

60. Dewey J. How We Think: A Restatement of the Relation of Reflective Thinking to the Educative Process. Boston, MA: DC Health; 1933.

61. Moon JA. A Handbook of Reflective and Experiential Learning: Theory and Practice. Abingdon, VA: Routledge; 2004.

62. Mezirow J. Transformative Dimensions of Adult Learning. San Francisco, CA: Jossey-Bass; 1991.

63. Brockbank A, McGill I. Facilitating Reflective Learning in Higher Education. 2nd ed. Berkshire, England: Society for Research into Higher Education and Open University Press; 2007.

64. Dunn L, Musolino GM. Assessing reflective thinking and approaches to learning. J Allied Health. 2011;40(3):128-136. 65. Lonie JM, Rahim H. Does the addition of writing into a pharmacy communication skills course significantly impact student communicative learning outcomes? A pilot study. J Pharm Pract. 2010;23(6):525-530.

66. Boud D, Keogh R, Walker D. Promoting reflection in learning: a model. In: Reflection: Turning Experience into Learning. London, Kogan Page; New York, NY: Nicols Pub; 1985:18-40.

67. IBMCorp. IBM SPSS Statistics for Windows. Version 20.0.

Armonk, NY: IBM Corp.; Released 2011.

68. McKauge L, Stupans I, Owen SM, Ryan G, Woulfe J. Building critical reflection skills for lifelong learning in the emergent landscape of a national registration and accreditation scheme. $J$ Pharm Pract. 2011;24(2):235-240.

69. Plack MM, Greenberg L. The reflective practitioner: reaching for excellence in practice. Pediatrics. 2005;116(6):1546-1552.

70. Hobson EH, Johnston PE, Spinelli AJ. Staging a reflective capstone course to transition PharmD graduates to professional life. Am J Pharm Educ. 2015;79(1):Article 14. 


\title{
American Journal of Pharmaceutical Education 2016; 80 (6) Article 101.
}

\author{
Appendix 1
}

Table 1. Student Perceptions of the Integration of the RACA ${ }^{\mathrm{a}}$ into Pharmacy Curriculum - a Retrospective Study

Instructions: Indicate the number that shows the extent to which you agree with each statement ${ }^{\mathrm{b}}$

The RACA involving the production of a video podcast with scenario writing and a reflective statement on the task, was challenging.

The RACA involving the production of a video podcast with scenario writing and a reflective statement helped me

become more interested in my learning in pharmacy.

The RACA helped me become a more self-directed learner.

I could see the relevance of the RACA to future clinical practice in pharmacy.

The RACA helped me improve my counseling skills.

The RACA provided me with the skills to perform to the best of my ability in the 2014 oral examination.

The introduction of reflective learning activities into my classes helped me see things from different perspectives.

${ }^{a}$ Reflective Ability Clinical Assessment

${ }^{\mathrm{b}} 1=$ strongly disagree; $2=$ disagree; $3=$ mildly disagree; $4=$ mildly agree; $5=$ agree; $6=$ strongly agree

Appendix 2

Table 1. Interview Guide for Focus Group/Interview Sessions

Did you feel that the Reflective Ability Clinical Assessment (RACA) worked well? If so, why? If not, why?

Did you feel that there were any limitations to the RACA?

What did you feel was the consensus from students about implementing the RACA?

How well did you feel that the introduction of the RACA enhanced student engagement in a task?

Would you make any changes to the RACA? If so, what would you suggest?

Do you think the RACA is a sustainable assessment strategy? If not, why? Do you have any suggestions for improvement? 
American Journal of Pharmaceutical Education 2016; 80 (6) Article 101.

Table 2. Student Perceptions of the Implementation of the RACA ${ }^{\mathrm{a}}$ into Pharmacy Curricula

\begin{tabular}{|c|c|c|c|c|c|c|c|}
\hline \multirow{2}{*}{$\begin{array}{l}\text { Questions Related to } \\
\text { Aspects of the RACA }\end{array}$} & \multirow{2}{*}{$\begin{array}{c}\text { Mean } \\
\text { [range 1-6] } \\
\text { (sd) }\end{array}$} & \multicolumn{6}{|c|}{ Percent of students in agreement } \\
\hline & & SD & D & MD & MA & $\mathbf{A}$ & SA \\
\hline The RACA was challenging. & $4.0(1.1)$ & 2.0 & 9.0 & 13.0 & 42.0 & 29.0 & 5.0 \\
\hline $\begin{array}{l}\text { The RACA helped me become } \\
\text { more interested in my pharmacy } \\
\text { learning. }\end{array}$ & $4.00(1.1)$ & 4.0 & 7.0 & 16.0 & 40.0 & 27.0 & 6.0 \\
\hline $\begin{array}{l}\text { The RACA helped me become } \\
\text { a more self-directed learner. }\end{array}$ & $4.1(1.1)$ & 4.0 & 5.0 & 14.0 & 38.0 & 33.0 & 6.0 \\
\hline $\begin{array}{l}\text { I could see the relevance of the } \\
\text { RACA to future clinical practice. }\end{array}$ & $4.6(1.2)$ & 3.0 & 3.0 & 5.0 & 28.0 & 40.0 & 21.0 \\
\hline $\begin{array}{l}\text { The RACA helped me improve my } \\
\text { counseling skills. }\end{array}$ & $4.5(1.1)$ & 2.0 & 3.0 & 9.0 & 27.0 & 44.0 & 15.0 \\
\hline $\begin{array}{l}\text { The RACA provided me with the } \\
\text { skills to perform to the best of my } \\
\text { ability in the } 2014 \text { oral } \\
\text { examination. }\end{array}$ & $4.2(1.2)$ & 4.0 & 5.0 & 13.0 & 33.0 & 35.0 & 10.0 \\
\hline $\begin{array}{l}\text { The introduction of reflective } \\
\text { learning activities into my classes } \\
\text { helped me see things from } \\
\text { different perspectives. }\end{array}$ & $4.1(1.11)$ & 2.0 & 5.0 & 18.0 & 40.0 & 26.0 & 9.0 \\
\hline
\end{tabular}

${ }^{a}$ Reflective Ability Clinical Assessment

${ }^{\mathrm{b}} \mathrm{sd}=$ standard deviation, $\mathrm{SD}=$ strongly disagree, $\mathrm{D}=$ disagree, $\mathrm{MD}=$ mildly disagree, $\mathrm{MA}=$ mildly agree, $\mathrm{A}=$ agree, $\mathrm{SA}=$ strongly agree

Table 3. Correlations of Measures for Survey Questions (Q)

\begin{tabular}{lccccccc}
\hline Measures & Q1 & Q2 & Q3 & Q4 & Q5 & Q6 & Q7 \\
\hline Q1 & - & & & & & & \\
Q2 & $0.28^{* *}$ & - & & & & & \\
Q3 & $0.29^{* *}$ & $0.74 * *$ & - & & & & \\
Q4 & $0.18^{* *}$ & $0.54 * *$ & $0.59^{* *}$ & - & & & \\
Q5 & $0.22^{* *}$ & $0.52^{* *}$ & $0.5 * *$ & $0.61 * *$ & - & & \\
Q6 & 0.13 & $0.54 * *$ & $0.54 * *$ & $0.60^{*}$ & $0.64 * *$ & - & \\
Q7 & $0.19^{* *}$ & $0.38^{* *}$ & $0.45^{* *}$ & $0.28^{* *}$ & $0.25^{* *}$ & $0.28^{* *}$ & - \\
\hline
\end{tabular}

*Correlation is significant at the 0.05 level *(2 tailed); 0.01 level

$* *(2$-tailed) 